\title{
Pediatric procedures in urology residency training: finding the balance between relevant and attainable competency
}

\author{
Karen Psooy, MD, FRCSC, DABU
}

See related article on page 205

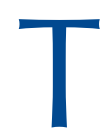

he recent survey by Mickelson and colleagues ${ }^{1}$ raises some interesting questions about the future of pediatric procedures being performed by our graduating urologists. Although the introduction of the American Board of Urology's certificate of added qualification in pediatric urology has the potential to impact referral and practice patterns for American urologists in a stepwise fashion, it is less likely to have a notable impact in Canada. However, there is a general trend toward subspecialization in urology, such that the definition of the "general" urologist, including the procedures they should and will be performing, is evolving.

The Royal College of Physicians and Surgeons of Canada (RCPSC) Objectives of Training in Urology ${ }^{2}$ are currently under review by the RCPSC Specialty Committee in Urology, and a number of pediatric procedures are being considered for reallocation of their status as "List A" or "List B" procedures. As a program director, member of the Pediatric Urologists of Canada (PUC) and member of the RCPSC Nucleus Committee in Urology, I see the importance of the objectives being both 1) based on the surgical skills required to be a competent general urologist and 2) attainable within the residency program. This is not always an easy balance to strike. The survey provides some guidance on this issue; it reports that while residents feel competent to perform $76 \%$ of the "List $A^{\prime \prime}$ procedures in children, they anticipate actually performing less than one-half of these procedures following graduation. This suggests that it is likely practice pattern, and not competence, that determines whether pediatric procedures will be performed by our graduates; however, as the authors point out, a survey of recently graduated urologists would provide a better answer. On the assumption that most of our graduates are unlikely to perform many pediatric procedures, it would then seem reasonable to downgrade the competency required for certain procedures and thus ensure attainability within the current pediatric exposure, rather than increase this exposure.

The ability to attain the objectives is also influenced by practice patterns, which are ever-changing. Shifting practice patterns likely had an impact on resident exposure to the "controversial" "List A" procedures. Surgical interventions that became popular following routine use of antenatal ultrasound are performed less frequently now as we learn the natural history of antenatal hydronephrosis. Therefore, pyeloplasties and heminephrectomies are done less commonly in infants and, when done, might be done laparoscopically. The number of augmentation cystoplasties performed annually at our centre has declined with emerging concerns about late malignancy and the introduction of tolerable high-dose anticholinergics. Finally, on a recent informal email survey, a number of PUC members reported that $90 \%$ of the procedures they perform for vesicoureteral reflux are now done endoscopically; a resident working at one of their centres would thus have more difficulty attaining competency to perform a "List $A$ " nonrefluxing open ureteroneocystostomy.

Should surgical planning for pediatric patients at teaching hospitals be influenced by the objectives or should the objectives be adjusted to reflect evolving practice patterns, both of urology graduates and of PUC members? This question requires consideration by the specialty committee. However, it stands to reason that the "general" urologist should be trained in what is generally done, and the less commonly performed procedures be left to the subspecialists.

From the Division of Pediatric Urology, Winnipeg Children's Hospital, Winnipeg, Man.

Competing interests: None declared.

\section{References}

1. Mickelson JJ, MacNeily AE, Samarasekera D, et al. Competence in pediatric urology upon graduation from residency: perceptions of residents, program directors and pediatric urologists. CUAJ 2008;2:205-10.

2. The Royal College of Physicians and Surgeons of Canada. Objectives of training. Available: http://rcpsc.medical.org/information/index?specialty=360\& submit=Select (accessed on 2008 Apr 2).

Correspondence: Dr. Karen Psooy, FE011-840 Sherbrook St., Winnipeg MB R3A 1S1; KPsooy@exchange.hsc.mb.ca 